\title{
Femoral Lenghtening with Precice Magnetic Nail in a 42 Year Old Patient
}

\author{
Mahmut Nedim Aytekin*, Fahri Emre and Safa Kapıcıoğlu \\ Department of Orthopedics and Traumatology, Medicine Faculty, Ankara Yildirim Beyazit University, Turkey
}

*Corresponding author : Assoc Prof Mahmut Nedim Aytekin, MD, Department of Orthopedics and Traumatology, Medicine Faculty, Ankara Yildirim Beyazit University, Turkey.

Received Date: April 09, 2019

Published Date: April 22, 2019

\begin{abstract}
Lower extremity length difference causes orthopedic pathologies as well as a cosmetic problem. Orthopedic surgeons are closely related to the treatment of this pathology due to changes in walking patterns and as well as degenerative disorders emerging in the skeleton. The treatment of the length difference in the lower extremity has not been commonly preferred amongst surgeons due to possible complications [1]. There, were subsequent periods of different treatments in orthopedic history. Amongst these treatment methods, the extension of the short limb was frequently performed before, but it was set aside when the complications occurred [2]. Then, in parallel with technological developments, they have become more current and widespread. In this case, we reported that extremity inequality caused coxarthrosis in the hip joint of the long side, although the patient was 42 years old, the extension could be successful with magnetic nails, and the precice nail could be broken from the extension point..
\end{abstract}

Keywords: Precice magnetic nail; Lenghtening

\section{Introduction}

Shortness of extremity due to different causes is a problem that can affect human life functionally and psychologically. There are many methods used in orthopedic surgery to enable these patients to have an aesthetic and functional extremity. Recently the popularity of magnetic extension with intramedullary nails has increased and its use has become widespread [3].

\section{Case Representation}

A 42-year-old male patient presented with left coxarthrosis and a shortness of $8 \mathrm{~cm}$ in the right femur. First, total hip arthroplasty was performed on the left side (Figure 1). Two months after the operation, osteotomy and magnetic extension nail were applied on the right femur per the patient's request. (Precice ${ }^{\circledR}$ Non Invasive Intramedullary Limb Lengthening System) (Figure 2). The patient was trained, and the extension was made with an external magnetic effect of $1 \mathrm{~mm}$ per day. The calculation was made using the length graphs and $8 \mathrm{~cm}$ extension was aimed, but when the $7 \mathrm{~cm}$ extension was achieved, the extension was terminated due to the onset of numbness on the foot. The bone cavity that was formed after the extension was observed to be filled with time (Figure 3,4). With no complaints from the patient, the crutch was terminated at 6 months. The patient walked with the full load without hobbling and without a cane. Two years later, the nail was broken through the osteotomy line without trauma (Figure 5). The extension nail was removed and replaced with a thicker intramedullary nail (nonmagnetic) (Figure 6). In the postoperative first year, the patient was provided with the complete bone union and full walking without a cane (Figure 1-7).

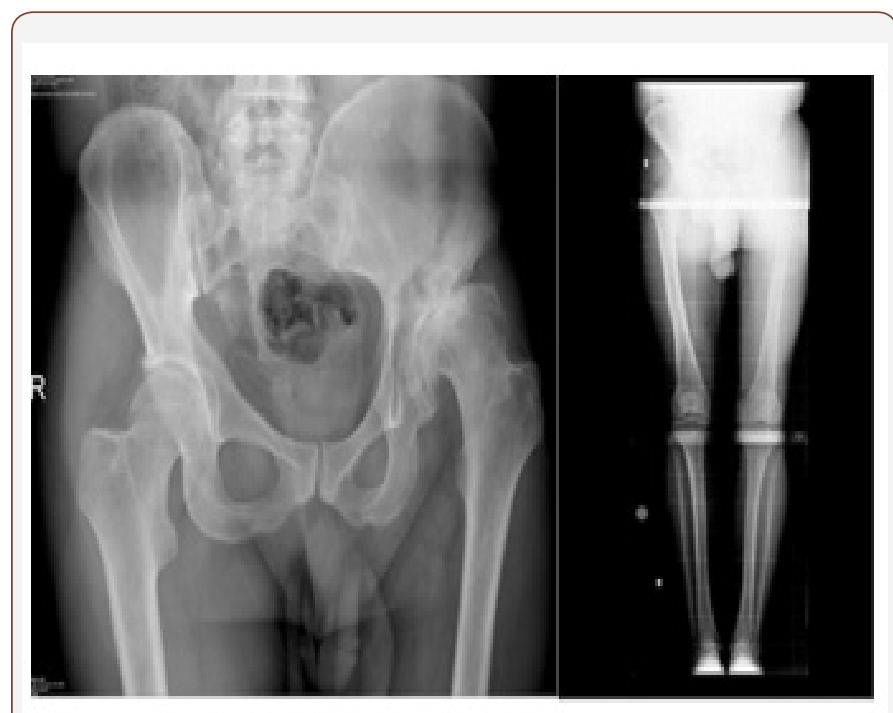

Figure 1: Preop X-Rays. 


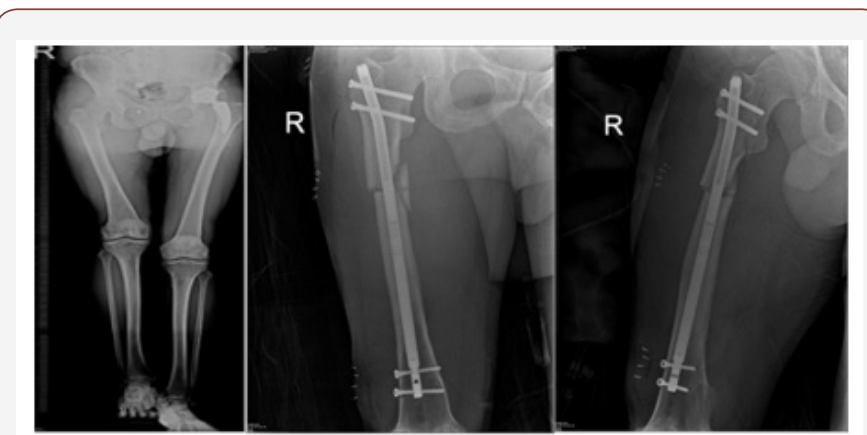

Figure 2: Postop $1^{\text {st }}$ Day X-Rays.

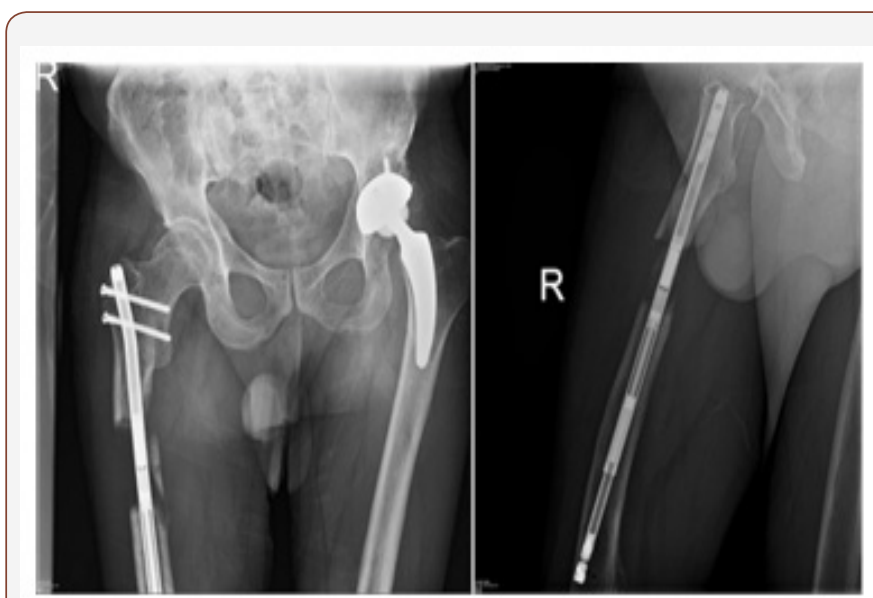

Figure 3: Postop $2^{\text {nd }}$ Month.



Figure 4: Postop $6^{\text {th }}$ Month.

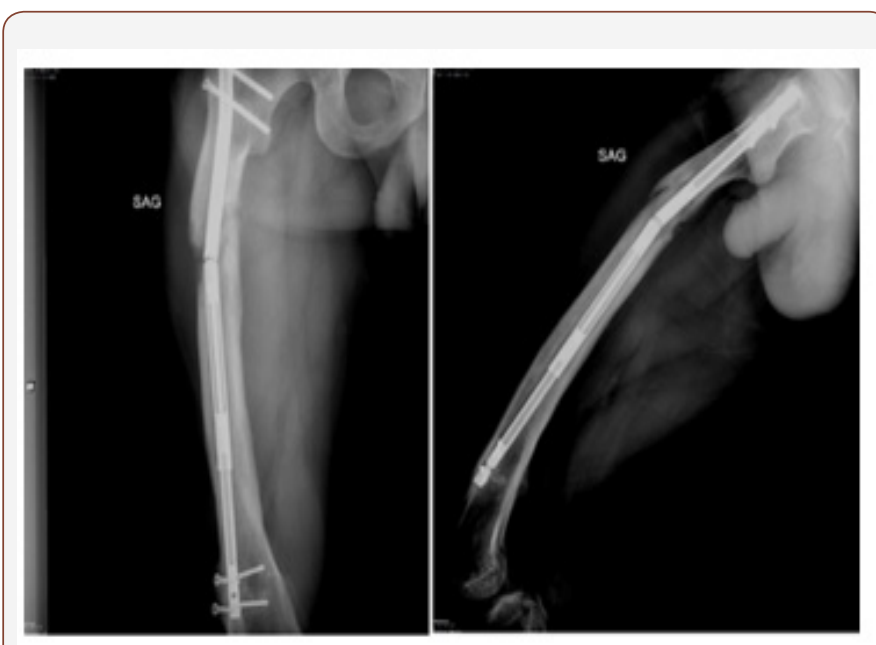

Figure 5: Postop $2^{\text {nd }}$ Year.

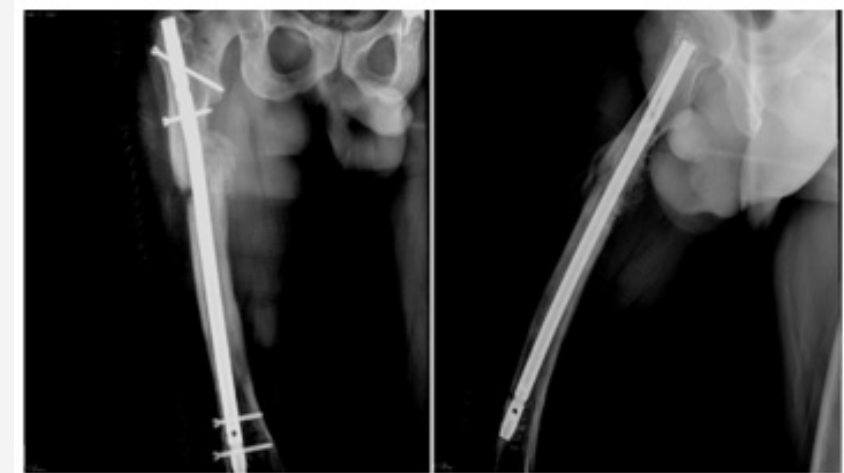

Figure 6: $2^{\text {nd }}$ Surgery Postop $1^{\text {st }}$ Day X-Rays.

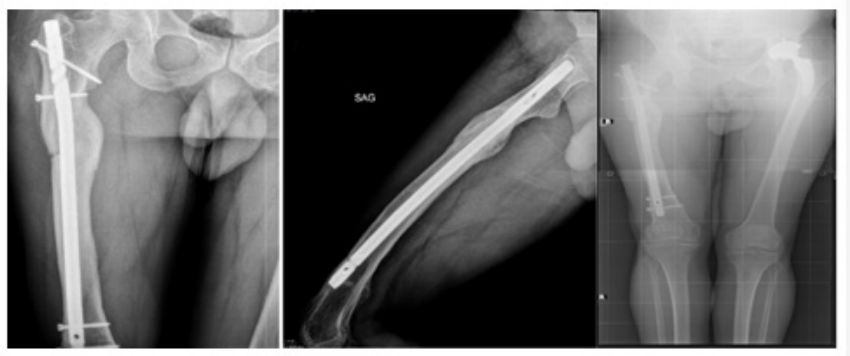

Figure 7: $2^{\text {nd }}$ Surgery Postop $6^{\text {th }}$ Month X-Rays.

\section{Findings and Remarks}

Treatments for the length difference of the extremities and dwarfism and their pathologies are very troublesome for both the patient and the surgeon. Many bone extension methods have been developed and applied in various centers around the world to solve these problems. In parallel with the development of technology, this process is getting better and richer with new methods. Limb lengthening techniques are used to replace the bone loss, to correct deformed(curved) bones and to extend bones [4]. These interventions can be applied to children or adult patients (between 3 and 70 years of age) who have developed arm and leg disparities after congenital disease, bone loss or trauma [5].

Extremity extension has gained significant improvements in recent years with the principles of "distraction osteogenesis". In this procedure, bone is cut gradually by surgical intervention and new bone formation (osteogenesis) is observed in the extension area. In this way, the bone can be extended between 15 and $100 \%$ of its length [6]. Until recently, intramedullary nails could not be used alone in the limb extensions and an extension was performed with the help of an external fixator. However, due to the presence of various complications in the use of external fixators, many studies have been carried out on the development of intramedullary nails that can provide an extension without the use of external fixators. In all these studies, various complications such as difficulties in patient mobility and insufficiency of mechanisms that provide extension, application difficulties and infection have emerged. Since limb height inequality is an obvious deformity as well as the fact that it will be solved by elongation of the bones, there have been many studies on the extension. Surgical elongation of long bones has been enriched by a variety of alternative methods in which the 
development process exceeds a century. Innovations in technology and the implants used are continuously enriched in parallel with the developments [7].

During the extension, preservation of the sequence, prevention of refracture and prevention of length loss after extension, providing high patient comfort even when applied on the femur and more range of motion of the joints are amongst magnetic nails advantages [8]. After total hip replacement surgery, sometimes one leg may be felt longer or shorter than the other. Maximum effort is made to ensure that your legs are equal during surgery, but sometimes your leg may be extended or shortened to increase hip stability and restore normal hip biomechanics. Therefore, in this case, the hip prosthesis was applied before the extension. Total hip arthroplasty and magnetic extension nail are examples of the high success achieved by today's medical technology. In this case, the patient who had right femur shortness and left coxarthrosis had a total hip arthroplasty on the left hip and a magnetic extension nail to the right femur.

When an extension of $7 \mathrm{~cm}$ was made with an extension of 1 $\mathrm{mm}$ a day, the extension was terminated as the numbness of the foot occurred on the same side. Walking without the support and end of the hobbling has been achieved. Hip and back pain is also healed. In the second year of the operation, the extension nail was broken from the osteotomy line without trauma. That complication was also reported before our case [9]. Extension nail was removed and replaced with a thicker nail. Fracture union happened in the third month of post op and the patient is walking without hobbling and without support. Hip and back pain ended. We did not find any similar cases in the literature and we wanted to share our case which shows magnetic internal extension nail can be successfully applied over 40 years of age. In this case, we reported that extremity inequality caused coxarthrosis in the hip joint of the long side, although the patient was 42 years old, the extension could be successful with magnetic nails, and the precice nail could be broken from the extension point.

\section{Acknowledgement}

None.

\section{Conflict of Interest}

No conflict of interest.

\section{References}

1. Aaron A, Weinstein D, Thickman D, Eilert R (1992) Comparison of orthoroentgenography and computed tomography in the measurement of limb length discrepancy. J Bone Joint Surg Am 74(6): 897-902.

2. Aldegheri R, Trivella G, Renzi Brivio L, Tessari G, Agostini S, et al. (1988) Lengthening of the lower limbs in achondroplastic patients. A comparative study of four techniques. J Bone Joint Surg Br 70(1): 69-73.

3. Terjesen T, Benum P, Rossvoll I, Svenningsen S, Fløystad Isern AE, et al. (1991) Leg length discrepancy measured by ultrasonography. Acta Orthop Scand 62(2): 121-124.

4. Paley D, Herzenberg JE, Paremain G, Bhave A (1997) Femoral lengthening over an intramedullary nail. A matched-case comparison with Ilizarov femoral lengthening. J Bone Joint Surg Am 79(10): 1464-1480.

5. Tetsworth K, Krome J, Paley D (1991) Lengthening and deformity correction of the upper extremity by the Ilizarov technique. Orthop Clin North Am 22(4): 689-713.

6. Tetsworth K, Paley D (1995) Basic sciense of distraction histogenesis. Current opinion in Orthopaedics 6(6): 61-68.

7. Baumgart R, Betz A, Schweiberer L (1997) A fully implantable motorized intramedullary nail for limb lengthening and bone transport. Clin Orthop Relat Res 343: 135-143.

8. Bost FC, Larsen LJ (1956) Experience with lengthening of the femur over an intramedullary rod. J Bone Joint Surg Am 38-A (3): 567-584.

9. Tiefenböck TM, Wozasek GE (2015) Unusual complication with an intramedullary lengthening device 15 months after implantation. Injury 46(10): 2069-2072. 